\title{
LA RACION PROTEICA EN EL TRATAMIENTO DE LOS TRASTORNOS NUTRITIVOS CRONICOS DEL LACTANTE
}

\author{
Prof. ANGel S. SEgura y Dr. PABLo ConstantinI \\ Hospital de Niños de Córdoba, Argentina.
}

\section{INTRODUCCIÓN}

En nuestro medio, los trastornos nutritivos crónicos integran una buena proporción de la patología del lactante. Trastornos que plantean en muchos casos problemas terapéuticos difíciles de solucionar, especialmente cuando el grado de la desnutrición es bastante acentuado. A esa dificultad terapéutica deseamos referirnos en este trabajo.

En las salas de lactantes notábamos, desde muchos años a esta parte, que los éxitos en el tratamiento de las distrofias graves, prolongadas, eran poco satisfactorios. Habíamos ensayado varias dietas, la mayoría ricas en calorías, proteínas y sales, pero relativamente pobres en grasas; con esos regímenes los niños frecuentemente permanecían durante meses en las salas y a pesar de numerosas pruebas el peso se mantenía estacionado o apenas aumentaba unos gramos.

Ese hecho indujo a uno de nosotros (P. C.) a ensayar con la vieja sopa Czerny a la cual introdujo algunas modificaciones en su preparación. Los buenos resultados obtenidos fueron la punta del hilo que nos llevó, poco a poco, al concepto que tenemos actualmente respecto al tratamiento de los lactantes desnutridos y que sometemos a consideración.
Previamente recordaremos y destacaremos algunas características de las distrofias y ciertos aspectos de la nutrición que nos parecen fundamentales para planear el tratamiento correcto de ese síndrome.

No se discute que al distrófico hay que proporcionarle una mayor cantidad de calorías que las necesarias para un niño normal de igual peso. Esto se comprende fácilmente: algunos desnutridos graves pueden tener un metabolismo basal más bajo que el niño normal (Key ${ }^{1}$; Olive Badosa $^{2}$ ), otros lo tienen alto (Olive Badosa ${ }^{2}$ ). Pero cuando se la trata y mientras se recupera, es lógico que el metabolismo suba. En ese momento de la enfermedad, la superficie corporal es mayor que la normal en relación al peso y por ende se pierde más calor por radiación. Por otra parte, la rápida reparación y neoformación de tejidos exige una tasa de "calor de crecimiento" superior a la normal. E1 alimento curativo que reciban los pacientes en esas condiciones debe cubrir esa mayor demanda de calorías.

El sistema digestivo del niño tiene un menor margen de seguridad (Marriott ${ }^{3}$ ). Como consecuencia de la desnutrición la capacidad digestiva disminuye. El distrófico tiene, pues, una potencia digestiva subnormal y por lo tanto el alimento terapéutico debe ser de fácil digestión. 
Para curarse, el distrófico debe crecer diariamente lo que le corresponde de acuerdo a su edad, más un tanto por ciento del peso que ha perdido o dejado de ganar en el tiempo oportuno. En otras palabras, debe progresar más que un niño normal. Para hacerlo no sólo necesita las "calorias de crecimiento", sino también los elementos plásticos esenciales, es decir, proteínas y sales. Esa mayor necesidad es un concepto universalmente aceptado y que se encuentra en todos los textos de Pediatría.

Cuando ahondando nuestra investigación nos preguntamos, ¿hasta cuánto podemos enriquecer con proteínas el régimen para los distróficos? Las respuestas son proco precisas. Algunos autores sólo mencionan las características de las dietas sin dar cifras (Finkelstein ${ }^{4}$, Glanzmann ${ }^{5}$, Fanconi y Wallgren ${ }^{6}$, Holt ${ }^{7}$ ). Otros, Schweizer 9 entre ellos, dicen alimentos ricos en proteínas $y$ sales como babeurre y leche albuminosa, de los cuales se puede llegar a dar 200 gr, por kilogramo y por día, es decir, aproximadamente $8 \mathrm{gr}$. de proteínas diarios por cada kilogramo de peso. Garrahan ${ }^{10}$ aconseja 4 a 5 gr. y Larguía 114 a 6 gr. de proteínas por kilogramo y por día. Por último, Darrow ${ }^{12}$ manifiesta que nunca vió progresar a un lactante con un régimen alimentario cuyo valor calórico estuviera cubierto en un $20 \%$ o más, por las proteínas.

Esa rápida revista bibliográfica confirma lo que dijimos más arriba: a los distróficos debemos darles más proteínas que a los niños sanos, pero no hay un concepto claro y preciso respecto al tenor de proteínas que deben tener las dietas curativas.

Las proteínas ingeridas como alimento, una vez absorbidas, pueden seguir tres caminos:

a) Una cierta cantidad de ellas es empleada para restaurar las proteínas tisulares que están constantemente destruyéndose y reparándose o para la formación de nuevos tejidos, es decir, para el crecimiento.

En términos generales se considera que para cada $30 \mathrm{gr}$. de aumento de peso, por neoformación de tejidos normales, principalmente de tejido muscular, se necesitan 6,25 gr. de proteínas, lo que equivale a decir 1 gramo de nitrógeno. b) Otra porción se utiliza para la síntesis de substancias biológicamente activas: hormonas, fermentos, anticuerpos, etc.

c) El resto es empleado como material energético. Los aminoácidos son desaminados en el hígado. La porción amina es transformada en amoníaco y urea para asi ser eliminada. Las cadenas de carbonos que formaban el ácido aminado, una vez perdido su grupo amino, se transforman en hidratos de carbono o grasas.

En el organismo humano prácticamente no existen depósitos de proteínas. El hígado tiene una reserva muy reducida, la que se moviliza rápidamente en caso de aporte insuficiente; quizás las proteínas del plasma puedan también considerarse como otro pequeño depósito de emergencia.

Por lo tanto, las proteínas de los alimentos son utilizadas para la reparación y síntesis de tejidos, para la transformación de elementos biológicamente activos y como material energético, no pudiendo ser acumuladas en calidad de reservas.

Pero, el empleo de cantidades excesivas de proteínas como combustible es antieconómico y sobrecarga el trabajo del organismo. Es antieconómico, por cuanto siendo el valor específico dinámico de las proteínas alto, cuando una ración es rica en ellas, debe aumentarse hasta en un $10 \%$ las calorías, para cubrir ese gasto extra. Además, su combustión en el organismo produce, a más de anhídrido carbónico y agua, urea, amoníaco, creatina, ácido úrico, compuestos azufrados, etc., lo que equivale a decir substancias tóxicas que deben ser eliminadas por varios emuntorios, de los cuales el principal es el riñón.

Ahora bien, los desnutridos que se recuperan y Ios individuos que crecen tienen una mayor síntesis tisular y por ende mayor retención nitrogenada (Peter y Van Slyke ${ }^{13}$ ). El régimen alimentario de personas en esas circunstancias debe ser más rico en proteínas que el de un adulto sano. Esa mayor necesidad de proteínas tiene un límite y si nos pasamos de él los resultados son contrarios a los que estamos buscando.

Esa afirmación está respaldada por opiniones como la de Hoesslin ${ }^{14}$ quien dice: "cuando la dieta es enriquecida con proteínas por arriba del mínimun nitrogena- 
do de equilibrio, sólo una parte del nitrógeno extra es retenido y si se continúa aumentado, cada nuevo aumento es menos retenido que el anterior"; a lo cual agregan Peters y Van Slyke: "llegándose a un punto en el que ningún beneficio se obtiene con seguir aumentando las proteínas".

Es también muy interesante la opinión de Mitchell ${ }^{15}$ quien sostiene que el régimen más adecuado para el crecimiento, debe ser: "rico en calorías y con la menor cantidad de proteínas que produzca la máxima retención nitrogenada, partiendo de la base que no hay razón para pensar que el máximo crecimiento de los tejidos principales del organismo sea mayor que el crecimiento óptimo". Hay una cantidad más allá de la cual todo nuevo aumento en las proteínas de la dieta no es beneficioso sino, por el contrario, tiene un efecto deletéreo (Peters y Van Slyke $\left.{ }^{16}\right)$.

El régimen más apropiado para el tratamiento de los distróficos necesariamente debe tomar en cuenta los conceptos que preceden. Sobre todo recordaremos que tanto las calorías como las proteínas tienen un límite que no podemos sobrepasar.

No pudiendo aumentar mucho las pruteínas para completar las calorías necesarias, forzosamente el régimen debe ser excesivamente hidrocarbonado o conterer una determinada cantidad de grasas: nos inclinamos hacia la segunda alternativa.

Nuestra posición respecto a los alimentos que contienen grasas en cantidad adecuada debe modificarse. Como ellas retardan la evacuación gástrica $\mathbf{y}$ exageran tanto los procesos de fermentación como de putrefacción intestinal, sólo se las da$\mathrm{ba}$ en cantidades muy reducidas en las personas con perturbaciones del funcionamiento gastrointestinal.

Trabajos modernos de Chung ${ }^{17}$ demuestran que las grasas se absorben normalmente en los niños con diarrea; lo mismo pasa en los prematuros (Morales, Chung, Lewis, Messina y Holt ${ }^{18}$ ).

Por otra parte, aunque el metabolismo de las grasas es incompletamente conocido, se sabe ya que ellas a más de ser un excelente alimento energético, influencian favorablemente la utilización de la galactosa y el balance positivo del nitrógeno (Elvehjen y Krehl ${ }^{{ }^{y}}$ ). Una proporción adecuada de grasa en una dieta, pro- duce una retención nitrogenada mayor que cuando se reemplazan las grasas por cantidades isocalóricas de hidratos de carbono.

Teóricamente podemós sostener que una conveniente cantidad de grasa en el régimen es beneficiosa para los distróficos. Veremos más adelante los resultados prácticos.

Lo hasta aquí expuesto constituye las bases del régimen que proponemos, el cual debe ser: rico en calorías, con una cantidad óptima de proteínas y que contenga grasas en una medida apropiada.

\section{MÉTODO Y MATERIAL DE ESTUdTO}

Las calorias a cubrir las calculamos en 140 a 180 por kilogramo de peso del paciente, o bien 100 a 140 por kilogramo de peso término medio. Para calcular este último, sumamos el peso actual del niño y su peso teórico, es decir, el que debía tener de acuerdo a su edad y peso de nacimiento; a esa surna la dividimos por dos y el resultado nos da el peso término medio.

Ese sistema para calcular las calorías lo venimos usando desde hace muchos años, con variaciones en más y en menos; sin embargo, como ya lo dijimos al iniciar este trabajo, hasta hace poco tiempo, el éxito que obteníamos era muy relativo. Realmente consideramos haber dado un paso importante hacia el mejor tratamiento de las distrofias, cuando el régimen tenia no sólo las calorías necesarias sino también las proteínas en su proporción óptima.

Después de muchas pruebas creemos haber llegado a determinar que esa proporción óptima es de 2,5 a 3,5 gramos por kilogramo actual de peso. La hemos determinado basándonos únicamente en la respuesta de los enfermos tratados, valorando no sólo el progreso de peso, sino también la mejor inmunidad, las características de la piel, tejido celular subcutáneo, etc., en una palabra, la forma y rapidez con que el distrófico se aproxima al niño normal.

Quizás alguien nos objete diciendo que no habiendo hecho estudio del balance proteico, mal podemos hablar de cantidad óptima de proteínas. En favor del procedimiento usado sólo apelaremos al testimonio de Levine ${ }^{2 n}$, quien dice: "A más de la medida del balance nitrogena- 
do, si una dieta proporciona la cantidad adecuada de proteinas para el crecimiento, puede juzgarse por la rapidez y calidad del aumento de peso".

Farr ${ }^{21}$ estudió el tralance proteico en niños pequeños con síndrome nefrótico $\mathrm{y}$ observó que el balance positivo máximo lo conseguía con 3,1 gr. de proteína por kilogramo de peso; si les aumentaba la ingestión proteica a $4,1 \mathrm{gr}$. por kilogramo, el balance positivo disminuía a casi la tercera parte del alcanzado con $3,1 \mathrm{gr}$. por kilogramo.

Las cifras son muy similares a las nuestras y también nosotros comprobamos que si nos pasamos de $4 \mathrm{gr}$. de proteínas por kilogramo de peso, en general, el proceso de curación se hace jnás lento $\mathrm{y}$ hasta puede llegar a detenerse.

Calculamos en primer término las calorías totales que debemos darle al paciente. Luego las proteínas a razón de 2,5 a $3,5 \mathrm{gr}$. por kilogramo de peso. Las calorías proporcionadas por las proteínas las restamos de las totales y el sobrante lo llenamos con grasas e hidratos de carbono en cantidad adecuada, para que cada uno de esos elementos nos proporcione aproximadamente la mitad de las calorías necesarias.

Según el peso del niño, en un régimen así concebido, el 6 al $12 \%$ de las calorías estarán dadas por las proteínas, un 44 a 47\% por los hidratos de carbono y el otro 44 a 47 \% por las grasas.

Pudiera parecer una mezcla demasiado rica en grasa, pero los resultados justifican su uso. Hemos tratado distróficos en pleno veramo, en salas sin aire acondicionado $\mathrm{y}$ no hemos tenido inconvenientes. Más aún, en muchos casos este régimen parece regularizar las funciones digestivas aunque el paciente tuviera previamente tendencia a $\mathrm{Ia}$ diarrea.

El distrófico necesita mayor cantidad de sales que el niño normal. La leche de vaca, base de todos los alimentos curativos (salvo cuando se usa leche de mujer) proporciona cantidad sufíciente de esos elementos. Tratándose de niños mayorcitos los alimentos complementarios que deben darse: sopa, puré, etc., refuerzan más aún el aporte.

Debemos preocuparnos de que el paciente reciba todas las vitaminas que le sean necesarias.

Con este trabajo no pretendemos recomendar un determinado alimento ni una mezcla especial como tratamiento de las distrofias. Por el contrario, creemos que si el médico se toma el trabajo de hacer algunos cálculos (y vale la pena hacerlos) se puede modificar cualquiera de los alimentos comúnmente empleados y hacerlos que llenen los requisitos esenciales que terminamos de presentar. Basta para ello diluír más o menos, según el caso, los alimentos habituales y agregarles cantidades adecuadas de hidratos de carbono (nosotros usamos en la mayoría de los casos dextrino-maltosa) y de mantequilla derretida.

Veamos un ejemplo: niño distrófics grave de 5 meses de edad, que pesa $3 \mathrm{ki}-$ lógramos. Disponemos de una leche ácida en polvo con la siguiente composición: proteínas $17,3 \mathrm{gr} . / \%$, grasas $15,0 \mathrm{gr} \% / \mathrm{t}$, hidratos de carbono 59,5 gr. $\%$, sales minerales $4,3 \%$.

A ese enfermito podemos llegar a darle diariamente $600 \mathrm{gr}$. de esa leche ácida, preparada al 10\%, agregándole un $4 \%$ de dextrino-maltosa y $1,5 \%$ de mantequilla; el aporte al paciente será como sigue:

Leche ácida al $10 \%$, $600 \mathrm{gr}$.

Prot. H.C. Gr.

Dextrino maltosa $4 \%$

Mantequilla al 1.5

Total en gramos

Calorías

$10,5 \quad 35,75$

24,00

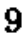

$10,5 \quad 59,75$

$42,0 \quad 236$

Esa mezcla proporciona al niño, por kilogramo de peso: $200 \mathrm{gr}$. de volumen, 146 calorías y 3,5 gramos de proteínas. El $54,1 \%$ de las calorías está aportado por los hidratos de carbono, el $36,5 \%$ por las grasas y el $9,4 \%$ por las proteínas. Régimen que llena todos los requisitos necesarios para el tratamiento de los distróficos. Las grasas en este ejemplo están bajas, podemos aumentarlas hasta que nos proporeionen alrededor del $45 \%$ de las calorías, sin ningún inconveniente $y$ frecuentemente con ventaja para el enfermo. Igual resultado podemos obtener utilizando un babeurre a la dilución conveniente $\mathrm{y}$ agregándole la cantidad necesaria de hidratos de carbono y grasas. Los mejores resultados los obtuvimos con sopa Czerny preparada con leche al medio y $3 \%$ de mantequilla, $3 \%$ de harina y $3 \%$ de azúcar.

Cuando decimos, podemos llegar a tal régimen, queremos significar que el tra- 
CUADRO N 1

\begin{tabular}{|c|c|c|c|c|c|c|c|c|}
\hline \multirow[b]{2}{*}{10} & & & & & & \multicolumn{3}{|c|}{ 7TOLECrda } \\
\hline & $x$ & $a_{1, m p}$ & 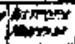 & 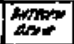 & 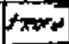 & $2 \pi$ & $\Delta x, m$ & $\overline{a x p r e}$ \\
\hline$\left[\begin{array}{l}0,5 \\
m m\end{array}\right.$ & 21 & 7 & 5 & 8 & 1 & 16 & 5 & - \\
\hline $\begin{array}{l}5.8 \\
\text { ifmr }\end{array}$ & 21 & 4 & 5 & 10 & 2 & 20 & 1 & - \\
\hline ists & 14 & 1 & 2 & $1 /$ & $=$ & 11 & 2 & 1 \\
\hline F & 5 & - & - & 5 & - & 5 & - & - \\
\hline Tor & 61 & 12 & $1 / 2$ & 34 & 3 & 52 & 8 & 1 \\
\hline
\end{tabular}

Resamen de nuestro material de enfermos $y$ de los resulcados obtenidos.

tamiento lo iniciamos en la forma clásica, con la hipoalimentación decreciente y sí e] niño tiene diarrea se la tratamos.

En otro trabajo nos ocuparemos de las dietas iniciales para el tratamiento de los trastornos nutritivos, pero desde ya podemos adelantar que, aion en esos primeros pasos, evitamos dar alimentos demasiados ricos en proteínas.

En las formas muy graves continuamos empleando el pecho en las primeras fases del tratamiento; con este alimento es fácil mantenerse dentro de las cantidades fijadas para las proteínas.

Nuestro material de enfermos está resumido en el cuadro No 1 . Los hemos clasificado de acuerdo a la edad y el grado de la distrofia.

No mencionamos la carencia alimentaria que extuvo más en juego por cuanto las reglas dadas las aplicamos a todos los casos, con mínimas variaciones que no sobrepasan los límites fijados. Por ejemplo, a una distrofia farinácea procuraremos aportarle un poquito más de proteínas que a una por exceso de leche, pero en general, no nos pasaremos de los $4 \mathrm{gr}$. por kilogramo y por día.

\section{FESULTADOS}

Consideramos los resultados muy buenos cuando rápidamente obteníamos un aumento de peso superior al que le corresponde de acuerdo a la edad; bueno cuando el aumento es el esperado para un niño normal de esa edad y mediocre cuando el progreso fué menor que el normal.

En la figura $N o$ mostramos la curva típica de un distrófico cuyo régimen contiene demasiadas proteínas. A este niño

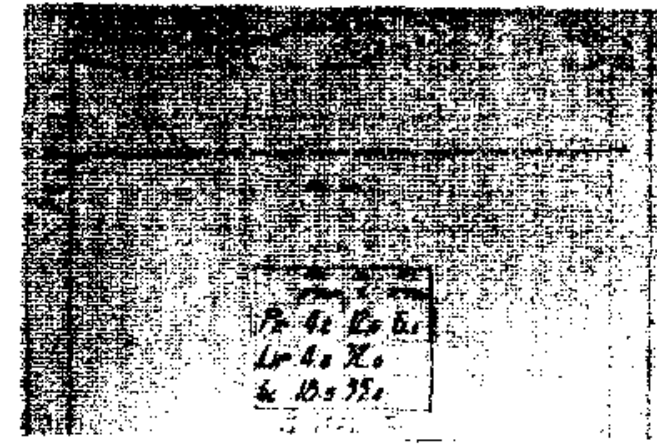

Figura No 1

Curva de peso de un niño tratado con excesira cantidad de proteínas.

se le daban 133 calorias por kilograma de peso término medio y 6,1 gramos de proteína por kilogramo de peso real. En 3 meses sólo progresó $200 \mathrm{gr}$.

En la figura $\mathrm{N}^{9} 2$ se ve el progreso de peso cuando a un distrófico le damos sólo 2,7 gramos de proteina por. kilogramo de peso.

La figura No 3 muestra la evolución de un paciente cuya gráfica de peso nos parece que proporciona datos muy ilustrativos cuando se la relaciona a lo que el niño comía en cada uno de los períodos en que hemos dividido el curso del tratamiento. Fué uno de los primeros enfermos de la serie. El temor a las diarreas, infecciones intercurrentes, etc., nos hizo cambiar varias veces el régimen alimentario. Se aprecia con toda claridad que cada vez que las proteínas fueron aumentadas más allá de lo que consideramos la cantidad óptima, el peso se estacionó.

Instamos a poner en práctica este procedimiento. La recolección de una gran cantidad de enfermos tratados con igual criterio revelará las bondades y defectos del método. Hasta el momento actual, con los fundamentos teóricos recopilados $y$ con lo observado en nuestro material de enfermos nos creemos autorizados a sostener con todo entusiasmo que las proteínas en los distróficos deben darse en cantidad de 2,5 a 3,5 gr. por kilogramo de peso real, pasarse de esa cifra en lugar de ser beneficioso retarda el proceso de curación. Las grasas dadas en cantidad moderada son de utilidad y no perturban el funcionamiento gastrointestinal.

Puede haber excepciones, distróficos que progresen con mayor cantidad de pro- 


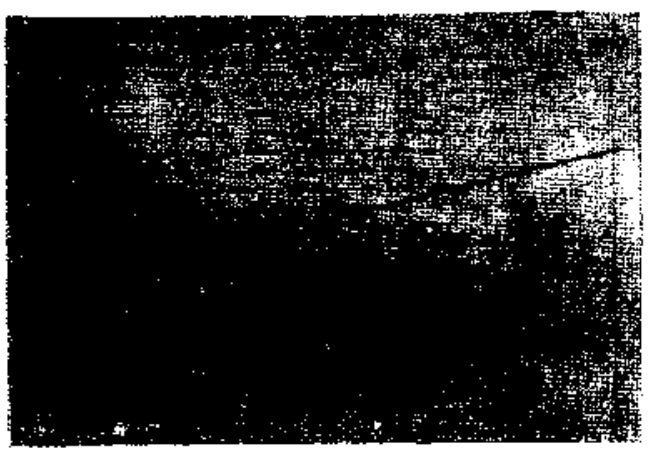

Figuta No 2 .

Muestra el progreso de peso de un niño distrófico al que se le daban las cantidades óptimas de proteinas.

teínas y quizás algunos que las necesiten; pero en medicina, si bien los tratamientos deben ser individuales, adaptados a un determinado enfermo, las normas generales se deducen de los resultados obtenidos en la mayoría de los casos, ése ha sido nuestro criterio al hacer este trabajo. La mayoría de los distróficos responderá bien a un tratamiento planeado siguiendo las directivas descriptas. Sólo en caso que el niño no progrese aun aumentando hasta un limite prudencial el valor calórico de la dieta, recién entonces estamos autorizados a sobrepasar las cantidades óptimas de proteínas y siempre pensando que el fracaso del tratamiento puede ser porque alguna causa orgánica se nos haya pasado por alto $y$ que el factor "ex morbo". esté en juego.

\section{RESUMEN}

Buscando encontrar un régimen alimentario que mejorara los resultados obtenidos en el tratamiento de los trastornos nutritivos crónicos del lactante se llegó a la siguiente comprobación: el régimen más adecuado debe proporcionar 140 a 180 calorías y aportar 2,5 a $\mathbf{3 , 5} \mathrm{gr}$. de proteínas por kilogramo de peso.

Esa cantidad de proteínas da un 6 a $12 \%$ del total de calorías necesarias, el resto lo cubrimos con hidratos de carbono y grasas. En forma de hidratos de carbono daremos el 44 a $47 \%$ de las calorías $y$ el otro 44 a $47 \%$ como grasas.

Los argumentos científicos y los resultados prácticos demuestran que los excesos de proteínas son perjudiciales. En la mayoría de los casos no se debe pasar de $\operatorname{los} 3,5 \mathrm{gr}$. por kilogramo y por día.

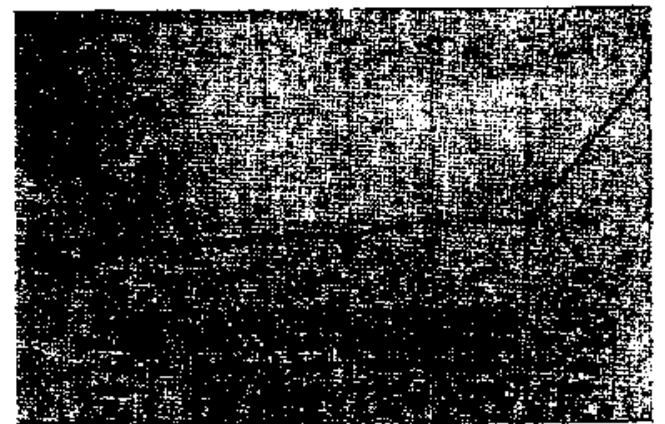

\section{Figura No 3.}

Niño de 4 meses de edad. El aumento de peso se retarda o estaciona cada vez que el régimen contiene demasiadas ptoteínas.

Excepcionalmente algunos niños pueden progresar con cantidades mayores.

Las grasas como integrantes del régimen, en medida adecuada, son beneficiosas. Se mencionan trabajos que avalan este concepto. No tuvimos inconvenientes con su empleo.

El aporte de sales está asegurado en la mayoría de los casos por el tipo de alimento empleado.

Deben darse las vitaminas necesarias.

Se pasa en rápida revista los resultados obtenidos los cuales se consideran muy satisfactorios.

\section{SUMMARY}

Looking for a nourishing system in order to improve the results obtained in the treatment of malnutrition in infancy, the author comes to verify the following: the most adequate diet must supply 140 to 180 calories and to provide 2,5 to 3,5 gr. of protein by kilogram of body weight.

This amount of proteins gives 6 to $12 \%$ of the whole necessary, and the remaining are provided by carbohydrates and fats. Carbohydrates must provide the 44 to $47 \%$ and fats other 44 to $47 \%$ of the whole calories.

Scientific argumentation and practical results show that an excessive amount of proteins is harmful. In the majority of the cases we must not surpass $3,5 \mathrm{gr}$. by kilogram of body weight daily. Exceptionally some children can progress with larger amounts.

Fats as component of diet, in adequate amount, are profitables. Some papers ratifying this conception are mentioned. 
The authors hadn't disadvantage with its use.

Salts are supplied in most of the cases by the type of food used.

Necessaries vitamins must be given.

A review of the results obtained is made, which are considered as satisfactories.

\section{BIBLIOGRAFÍA}

1.-KEY. A. "Diseases if metabolism" the Demenu $r$.

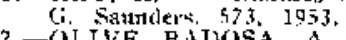

2.-OTIVE BATYOSA, $A$ - "La distrofia eniermedl

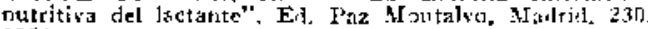
1954

3.-MAKRIOTT, W. ack. - "Infant nutrition". Mashy. 105,1435

4.-FINKLISTFIN, H. - "Trataclo de eniermedales ilel dactante". Latiot. 3(10), 1950.

5.-GLANZMANN. k. - "Leccimes the pelintria". Inibar. 175,1951

6.-FAXCoNi, G, y Wallgrex, A. - "Tratado de pediatria". Morata. Traducción al castellano, 155, 1953.

7.-HOLT, J. E., Jr. F Mc. INTOSH, k. $\rightarrow$ "Ho't's discases of infancy and childhood" ${ }^{\prime}$. Appleton, eleven edition. 238,1940 .

9.-SCHVEIZEK, F. - "Trastormos nutritivos tiel lactante". El Alento. 31Y, 1941.

10.-GaRkAFAN, ]. P - "Yedicina Infantil", in Edi-

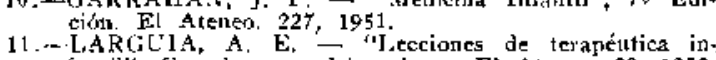
fantil". Gartahat y colahoradores. El Ateneo. 39. 1953.

12,-DARIKOW, t), c, - "Btennemann's Practice of Pe. diatríes", vol, 1, cap. 26, pás. 9.

13. - VETERS. J, P, and VAY SLYKE, D, D. - "Quat titative clinical clemistry" Vol. I. Ititerptetatiots, Wi liarss y Wilkins. $661,1946$.

14, ․ HOESSLIN, H, von. - Arch. Hyg, 1919, 88, 147. Citaclo por Petergy van Slyke (13), 660.

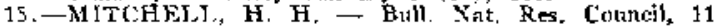
Part, 1, 1926, No 55, pág. 21. Cilaclo por l'etersy van Siyke (13), 658.

16, - I'ESFRE, J, P. and rat SLYKT, D, D, .- (13), 658 .

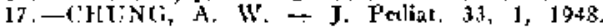

18. MURALES, S.; CHUNG, A. W.; J,EWIS. J. M.; MESSINA, A. y HOIT, J. E., Jr. - Pediatries. 7, 491,1951 . 19. - E.VEGJEH, C. A. Y KREII, W. H. - I.A.MA.

20.--LFVIXV. S. Z, - J.A.M.A. 12R, 283. 1945

21.-FAKR, L. E. - Am. J Hel Š, 195, 70, 1938, Ci. tadu por Yelers $y$ pan Silye (16). 